\title{
Selective Recovery of Radioactive Carbon Dioxide Released from Nuclear Off-gas by Adsorption"
}

\author{
Kenzo MUNAKATA $^{* *}$ and Akinori KOGA ${ }^{* *}$ \\ **Department of Advanced Energy Engineering Science, \\ Interdisciplinary Graduate School of Engineering Science, Kyushu University, \\ Hakozaki, Higashi-ku, Fukuoka 812-8581, Japan \\ E-mail: kenzo@nucl.kyushu-u.ac.jp
}

\begin{abstract}
Off gases produced in the reprocessing of spent nuclear fuel contain various radioactive gases and emission of these gases to the environment must be suppressed as low as possible. ${ }^{14} \mathrm{C}$ with a long half-life, which is mainly released as the form of carbon dioxide, is one of such gaseous radioactive materials. One of the measures to capture radioactive gases from the off-gas is the utilization of adsorption technique. In this work, the adsorption behavior of carbon dioxide on various adsorbents was studied. It was found that a MS4A (Molecular Sieve 4A) adsorbent is more suitable for selective recovery of carbon dioxide. Thus, more detailed adsorption characteristics of carbon dioxide were studied for a MS4A adsorbent. Moreover, the authors investigated the influence of coexistent water vapor, which is also contained in the off-gas, on the adsorption behavior of carbon dioxide.
\end{abstract}

Key words: Adsorption, Carbon Dioxide, Water Vapor, Nuclear Fuel Reprocessing, MS4A Adsorbent

\section{Introduction}

Reprocessing of spent nuclear fuel produces nuclear off-gases, which contains various radioactive gases. Emission of these radioactive gases to the environment should be suppressed as low as reasonably possible not only for protection against radiation but also for the advancement of public acceptance of the nuclear energy. The nuclear off-gases contain tritium as ${ }^{3} \mathrm{H}_{2}$ or tritiated water vapor, ${ }^{14} \mathrm{C}$ as carbon dioxide, ${ }^{85} \mathrm{Kr}$ and ${ }^{133} \mathrm{Xe}$ as chemically inert gases, ${ }^{129} \mathrm{I}$ as $\mathrm{I}_{2}$ or $\mathrm{CH}_{3} \mathrm{I}$ and so forth. At present, these radioactive gases are, however, released into the atmosphere except iodine. Among these radioactive gaseous elements, ${ }^{14} \mathrm{C}$ has the longest half-life and thus will continue to accumulate in the environment if the status quo for the off-gas treatment is maintained. For this reason, an efficient recovery system of carbon dioxide needs to be developed. The adsorption process could be one candidate to achieve this purpose. In this work, the authors investigated the adsorption characteristics of carbon dioxide on various adsorbents.

The nuclear off-gas and exhaust gases from industry or vehicles contain various gaseous components other than carbon dioxide. In practice, coexistent components such as nitrogen or water vapor may influence the adsorption behavior of carbon dioxide. In particular, water vapor would be one of the most influential components to the adsorption behavior of carbon dioxide. Therefore, the authors also investigated the adsorption behavior of carbon dioxide in the presence of water vapor.

*Received 3 Sep., 2007 (No. 07-0489) [DOI: 10.1299/jpes.2.178] 


\section{Nomenclature}

$\bar{a}_{i}$ : partial molar surface area, $\mathrm{m}^{2} / \mathrm{mol}$

$b_{i}$ : Henry's law constant, $\mathrm{mol} / \mathrm{g} \cdot \mathrm{Pa}$

$b_{0, i}$ : temperature independent constant for each adsorbate-adsorbent system, mol/(g.Pa)

$n_{i}^{s}:$ number of moles in surface phase, $\mathrm{mol} / \mathrm{g}$

$n_{i}^{s, \infty}$ : maximum number of moles of $i$ in surface phase, $\mathrm{mol} / \mathrm{g}$

$n_{m}^{s}$ : total number of moles of mixture in surface phase, $\mathrm{mol} / \mathrm{g}$

$n_{m}^{s, \infty}:$ maximum total number of moles of mixture in surface phase, $\mathrm{mol} / \mathrm{g}$

$p_{i}$ : partial pressure of $i$ in vapor phase, $\mathrm{Pa}$

$q_{s t, i}^{\theta}: \quad$ infinite dilution isosteric heat of adsorption of $i, \mathrm{~J} / \mathrm{mol}$

$R: \quad$ gas constant $(: 8.31), \mathrm{J} /(\mathrm{mol} \cdot \mathrm{K})$

$T:$ temperature, $\mathrm{K}$

$V_{i}^{L}:$ molar liquid volume, $\mathrm{m}^{3} / \mathrm{mol}$

$x_{i}:$ mol fraction in vacancy-free adsorbed phase

$y_{i}:$ mol fraction of in vacancy-free vapor phase

$\lambda_{i j}$ : pair interaction energy between $i$ and $j$ molecules for Wilson model, $\mathrm{J} / \mathrm{mol}$

$\theta:$ fractional coverage

$\gamma_{i}^{s}:$ activity coefficient in adsorbed phase

$\Lambda_{i j}$ : Wilson parameters for interaction between $i$ and $j$

\section{Subscripts}

$i$ : number of component $\left(1: \mathrm{CO}_{2}, 2: \mathrm{H}_{2} \mathrm{O}\right.$ and 3 : vacancy in binary adsorption system)

\section{Experimental}

Figure 1 shows the schematic diagram of the experimental apparatus used in this study. A helium gas containing a certain amount of $\mathrm{CO}_{2}$ was introduced to the adsorption bed. The adsorbents used in the experiments were synthetic zeolites such as MS3A (Molecular Sieve 3A, Aldrich), MS4A (Aldrich), MS5A (Kishida Kagaku) and MS13X (Kishida Kagaku) adsorbents. A natural mordenite adsorbent produced at Itado, Akita prefecture was also used. Water vapor was generated by passing $\mathrm{H}_{2} / \mathrm{He}$ gases through a copper monoxide bed at $623 \mathrm{~K}$. The concentration of $\mathrm{CO}_{2}$ in the inlet and outlet streams of the adsorption bed was measured with a gas chromatograph (Shimadzu GC8A) and the concentration of water vapor was measured with a hygrometer (Michell Transmet).

The adsorbents were dried or regenerated under pure helium gas streams. The regeneration

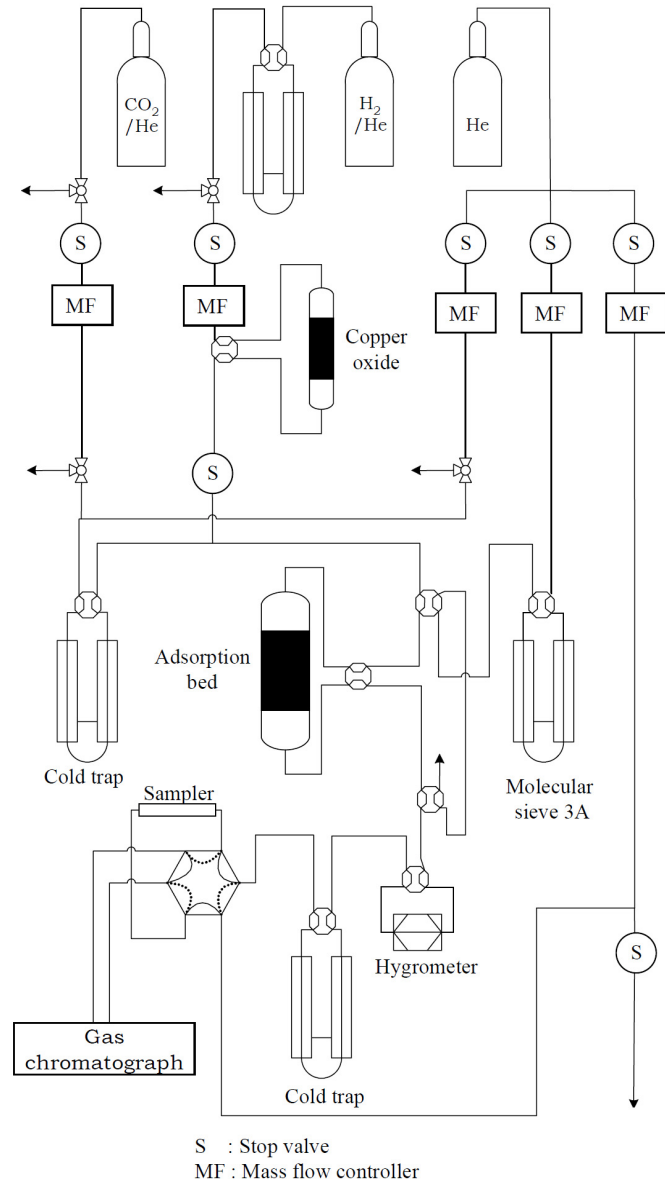

Fig.1 schematic diagram of experimental apparatus 
temperatures of the adsorbents were $523 \mathrm{~K}$ for synthetic zeolite $5 \mathrm{~A}$ and synthetic zeolite $13 \mathrm{X}$, and $623 \mathrm{~K}$ for the mordenites. The temperature of the adsorption column was controlled by immersing it in a constant temperature bath. The flow rate of the sample gas was controlled with conventional mass flow controllers. The process gases were pretreated with cold traps at $195 \mathrm{~K}$ or a MS3A adsorption bed to remove small amounts of water vapor which remained in the gases supplied from the gas cylinders before being introduced to the experimental system.

\section{Result and Discussion}

\subsection{Adsorption of $\mathrm{CO}_{2}$ on various adsorbents}

Figure 2 shows the amounts of $\mathrm{CO}_{2}$ adsorbed on various adsorbents at $273 \mathrm{~K}$ as the function of partial pressure of $\mathrm{CO}_{2}$. The adsorption amounts of $\mathrm{CO}_{2}$ were calculated from experimental breakthrough curves. As shown in the figure, great difference in adsorption capacity for $\mathrm{CO}_{2}$ is not seen among the adsorbents tested. The natural mordenite adsorbent appears to have largest adsorption capacity at lower partial pressure range of $\mathrm{CO}_{2}$. It was experimentally confirmed that the MS3A adsorbent has almost no adsorption capacity for $\mathrm{CO}_{2}$. This is probably due to the sieving effect; the micro-pore diameter of the MS3A adsorbent is $0.3 \mathrm{~nm}$ and thus the $\mathrm{CO}_{2}$ molecule cannot enter the adsorption site of the MS3A adsorbent. With regard to the adsorption capacity for $\mathrm{CO}_{2}$, the natural mordenite adsorbent is a promising candidate. However, in the nuclear off-gas, other radioactive gases such as $\mathrm{Kr}$ and $\mathrm{Xe}$ are also coexistent, and thus the adsorption characteristics of these gases need to be considered as well. A pervious study suggests that the natural mordenite adsorbent has larger adsorption capacity for $\mathrm{Kr}$ and $\mathrm{Xe}^{(1)}$. The MS5A adsorbent also has moderate adsorption capacity for $\mathrm{Kr}$ and $\mathrm{Xe}^{(2,3)}$. Therefore, the adsorption capacity of $\mathrm{Kr}$ on the adsorbent tested was examined, and it was found that the MS4A adsorbent has almost no adsorption capacity for $\mathrm{Kr}$. It is also probably due to the sieving effect of the MS4A adsorbent. The micro-pore diameter of the MS4A adsorbent is $0.4 \mathrm{~nm}$ and thus the $\mathrm{Kr}$ molecule cannot enter the adsorption site since the kinetic diameter of $\mathrm{Kr}$ is about $0.4 \mathrm{~nm}$ that is comparable to the micro-pore diameter of the MS4A adsorbent. The kinetic diameter of $\mathrm{Xe}$ is greater than that of $\mathrm{Kr}$, and thus the MS4A adsorbent could have no adsorption capacity for Xe. From the viewpoint of the separative recovery of $\mathrm{CO}_{2}$, the MS4A adsorbent has an advantage over other adsorbents regardless of its modest adsorption capacity for $\mathrm{CO}_{2}$. For this reason, the authors further studied the adsorption characteristics of $\mathrm{CO}_{2}$ on the MS4A adsorbent.

\subsection{Adsorption isotherm of $\mathrm{CO}_{2}$ on MS4A adsorbent}

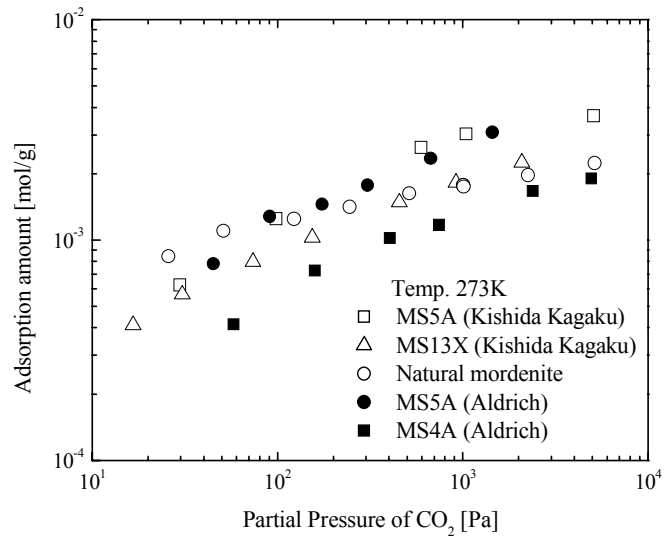

Fig.2 Adsorption amount of $\mathrm{CO}_{2}$ on various adsorbent at $273 \mathrm{~K}$

The adsorption amount of $\mathrm{CO}_{2}$ on the MS4A adsorbent was examined at the temperatures of 195, 273, 303, 353 and $403 \mathrm{~K}$. Figure 3 shows the adsorption amount of $\mathrm{CO}_{2}$ on the MS4A adsorbent as the function of partial pressure of $\mathrm{CO}_{2}$ and temperature. It is seen that the adsorption amount of $\mathrm{CO}_{2}$ little decreases with decreasing partial pressure of $\mathrm{CO}_{2}$ at $195 \mathrm{~K}$. Thus, it can be said that the MS4A adsorbent has a higher adsorption 
capacity for $\mathrm{CO}_{2}$ if the adsorption temperature is lowered. The adsorption isotherm shown in Fig. 3 was first correlated with the Langmuir equation, and the result of the correlation was shown as solid lines in the figure. The result indicates that the Langmuir equation is not appropriate for correlation of the experimental adsorption isotherm. Next, the authors tested the vacancy solution model $^{(4)}$, which is expressed as

$$
\begin{aligned}
& p_{1}=\frac{n_{1}^{s, \infty}}{b_{1}} \frac{\theta}{1-\theta}\left[\Lambda_{13} \frac{1-\left(1-\Lambda_{31}\right) \theta}{\Lambda_{13}+\left(1-\Lambda_{13}\right) \theta}\right] \exp \left[-\frac{\Lambda_{31}\left(1-\Lambda_{31}\right) \theta}{1-\left(1-\Lambda_{31}\right) \theta}-\frac{\left(1-\Lambda_{13}\right) \theta}{\Lambda_{13}+\left(1-\Lambda_{13}\right) \theta}\right] \\
& x_{1}^{s}=\frac{n_{1}^{s}}{n_{1}^{s, \infty}}=\theta \\
& b_{1}=b_{0,1} \exp \left(-\frac{q_{s t, 1}^{\theta}}{R T}\right)
\end{aligned}
$$

First, the effect of temperature on the Wilson parameters were neglected and the parameters, $b_{0,1},-q_{s t, 1}^{\theta}, n_{1}^{\infty}, \Lambda_{31}$ and $\Lambda_{13}$ were determined using the least squares analysis (Levenberg Marqurt method). The result of correlation was shown as broken lines in Fig. 3. The experimental adsorption isotherm was appropriately correlated with the vacancy solution model. Next, the temperature effect on the Wilson parameters was examined using the following equation.

$$
\begin{aligned}
& \Lambda_{13}=\frac{V_{3}^{L}}{V_{1}^{L}} \exp \left\{\frac{-\left(\lambda_{13}-\lambda_{11}\right)}{R T}\right\} \\
& \Lambda_{31}=\frac{V_{1}^{L}}{V_{3}^{L}} \exp \left\{\frac{-\left(\lambda_{31}-\lambda_{33}\right)}{R T}\right\}
\end{aligned}
$$

In this case, the parameters, $b_{0,1}$, $-q_{s t, 1}^{\theta}, \quad n_{1}^{\infty}, \quad-\left(\lambda_{13}-\lambda_{11}\right)$, $-\left(\lambda_{31}-\lambda_{33}\right)$ and $\left(V_{1}^{L} / V_{3}^{L}\right)$ were optimized. The result of correlation is shown as chained lines in Fig. 3. The experimental isotherm was well correlated with the model, but difference in the correlativity between the temperature-independent Wilson parameter model and the temperature-dependent Wilson
Table1 Parameters optimized for vacancy solution model

\begin{tabular}{ccc}
\hline \multirow{2}{*}{ Parameter } & \multicolumn{2}{c}{ Molecular sieve 4A } \\
\cline { 2 - 3 } & $\mathrm{CO}_{2}$ & $\mathrm{H}_{2} \mathrm{O}$ \\
\hline$b_{0,1}[\mathrm{~mol} / \mathrm{g} \cdot \mathrm{Pa}]$ & $4.87 \times 10^{-12}$ & $4.92 \times 10^{-11}$ \\
$-q_{s t, 1}^{\theta}[\mathrm{J} / \mathrm{mol}]$ & $3.60 \times 10^{4}$ & $3.07 \times 10^{4}$ \\
$n_{1}^{\infty}[\mathrm{mol} / \mathrm{g}]$ & $5.16 \times 10^{-3}$ & $1.02 \times 10^{-2}$ \\
$\Lambda_{13}[-]$ & 3.19 & $6.43 \times 10^{-4}$ \\
$\Lambda_{31}[-]$ & 4.54 & 4.93 \\
\hline$b_{0,1}[\mathrm{~mol} / \mathrm{g} \cdot \mathrm{Pa}]$ & $8.71 \times 10^{-13}$ & $4.84 \times 10^{-13}$ \\
$-q_{s t, 1}^{\theta}[\mathrm{J} / \mathrm{mol}]$ & $4.15 \times 10^{4}$ & $5.88 \times 10^{4}$ \\
$n_{1}^{\infty}[\mathrm{mol} / \mathrm{g}]$ & $4.77 \times 10^{-3}$ & $1.10 \times 10^{-2}$ \\
$\left(V_{1}^{L} / V_{3}^{L}\right)[-]$ & 3.24 & 1.40 \\
$-\left(\lambda_{13}-\lambda_{11}\right)[\mathrm{J} / \mathrm{mol}]$ & $1.59 \times 10^{3}$ & $-1.61 \times 10^{4}$ \\
$-\left(\lambda_{31}-\lambda_{33}\right)[\mathrm{J} / \mathrm{mol}]$ & $1.36 \times 10^{3}$ & $5.17 \times 10^{3}$ \\
\hline
\end{tabular}


parameter model is not obvious. Thus, it can be said that the temperature effect on the Wilson parameter is small. The parameters optimized for the vacancy solution model is summarized in Table 1 .

\subsection{Adsorption of $\mathrm{H}_{2} \mathrm{O}$ on MS4A}

In order to investigate the effect of water vapor on the adsorption of $\mathrm{CO}_{2}$ on the MS4A adsorbent, the authors first studied the adsorption characteristics of $\mathrm{H}_{2} \mathrm{O}$ on the adsorbent. The experiment was also performed by the breakthrough method. Figure 4 shows the adsorption amount of $\mathrm{H}_{2} \mathrm{O}$ as the function of partial pressure of $\mathrm{H}_{2} \mathrm{O}$ and temperature. As shown in the figure, the saturation limit for the adsorption of $\mathrm{H}_{2} \mathrm{O}$ is twice as large as that for $\mathrm{CO}_{2}$. Additionally, it was found that the adsorption amount of $\mathrm{H}_{2} \mathrm{O}$ is more than 10 times larger than that of $\mathrm{CO}_{2}$ at the lower partial pressure range. Therefore, it was expected that the coexistence of water vapor considerably affects the adsorption characteristics of $\mathrm{CO}_{2}$. The adsorption isotherm shown in Fig. 4 was correlated with the Langmuir equation, but it was not successful (see solid lines in the figure). Thus, the vacancy solution model was used for the correlation of the experimental isotherm. The experimental isotherm was well correlated with the model (see broken and chained lines in Fig. 4), and in this case the temperature-dependent Wilson parameter model gave better correlation of the isotherm. The parameters optimized for $\mathrm{H}_{2} \mathrm{O}$ in the vacancy solution model was also

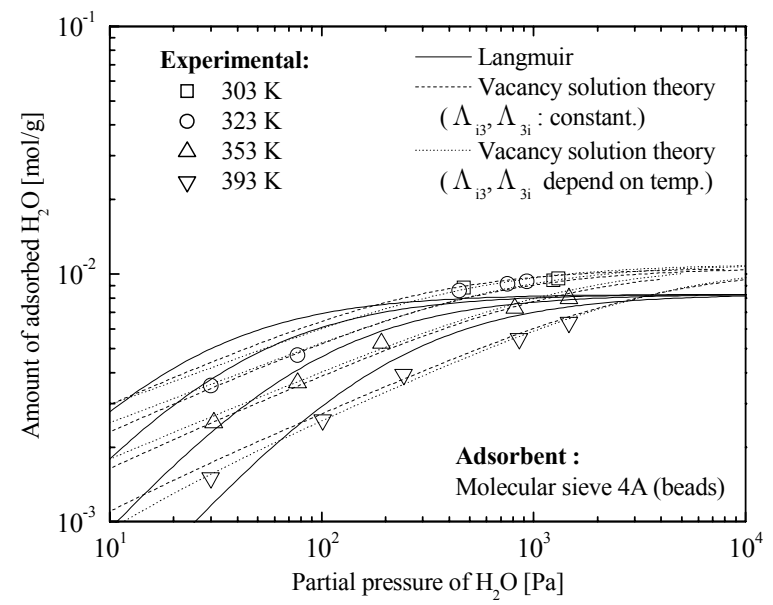

Fig.4 Adsorption amount of $\mathrm{H}_{2} \mathrm{O}$ on MS4A summarized in Table 1

\subsection{Effect of water vapor on adsorption of $\mathrm{CO}_{2}$ on MS4A}

The result shown the previous section indicates that the adsorption amount of water vapor is considerably larger compared with $\mathrm{CO}_{2}$ even when the partial pressure of $\mathrm{H}_{2} \mathrm{O}$ is small. Thus, the authors investigated the effect of coexistent water vapor on the adsorption amount of $\mathrm{CO}_{2}$ on the MS4A adsorbent. Breakthrough experiments were conducted for the $\mathrm{CO}_{2}-\mathrm{H}_{2} \mathrm{O}$ binary system. In the experiment, a helium gas containing a certain amount of $\mathrm{CO}_{2}$ and $\mathrm{H}_{2} \mathrm{O}$ was introduced to the adsorption bed. One example of the breakthrough curves is shown in Fig. 5; in this case the helium gas containing $34 \mathrm{~Pa}$ of

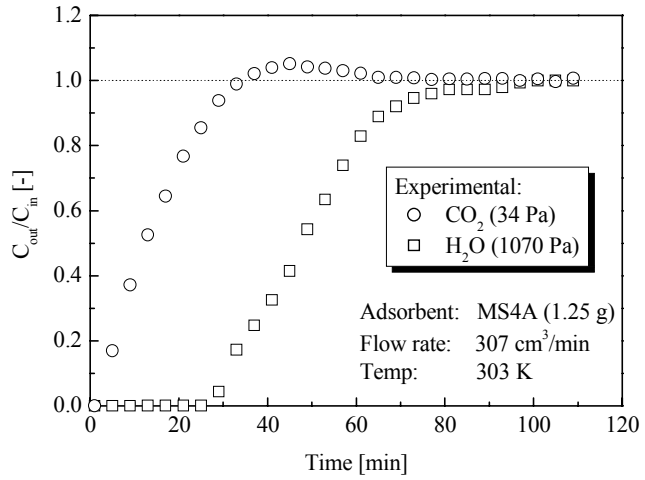

Fig.5 Breakthrough curve of $\mathrm{CO}_{2}-\mathrm{H}_{2} \mathrm{O}$ binary system on MS4A 
$\mathrm{CO}_{2}$ and $1070 \mathrm{~Pa}$ of $\mathrm{H}_{2} \mathrm{O}$ was introduced to the MS4A adsorption bed. In this figure, the concentration of $\mathrm{CO}_{2}$ and $\mathrm{H}_{2} \mathrm{O}$ in the outlet stream of the adsorption bed is normalized with their inlet concentrations. The breakthrough curve in Fig. 5 is that of typical binary system with different adsorption affinities. First, $\mathrm{CO}_{2}$ broke through earlier than $\mathrm{H}_{2} \mathrm{O}$. Secondary, the outlet concentration of $\mathrm{CO}_{2}$ became more than the inlet concentration as the breakthrough of $\mathrm{H}_{2} \mathrm{O}$ proceeded. This is because $\mathrm{H}_{2} \mathrm{O}$, which has a higher affinity to the MS4A adsorbent in comparison with $\mathrm{H}_{2} \mathrm{O}$, drove out adsorbed $\mathrm{CO}_{2}$ with advance in its adsorption. The experiments were performed by changing the partial pressure of water vapor and the effect of water vapor on the adsorption amount of $\mathrm{CO}_{2}$ was investigated.

Figures 6 (a) and (b) shows the effect of the partial pressure on the amount of $\mathrm{CO}_{2}$ adsorbed on the MS4A adsorbent at temperatures of 303 and $353 \mathrm{~K}$. The partial pressure of $\mathrm{CO}_{2}$ was held at about $36 \mathrm{~Pa}$, since the concentration of $\mathrm{CO}_{2}$ in the nuclear off-gas could be in this concentration range. The broken line in the figures represents the adsorption amount of $\mathrm{CO}_{2}$ without water vapor. As seen in these figures, the adsorption amount of $\mathrm{CO}_{2}$ decreases with increasing partial pressure of water vapor. However, decrease in the adsorption amount of $\mathrm{CO}_{2}$ takes place not so greatly. It was previously reported that the adsorption amount of $\mathrm{CO}_{2}$ on a natural mordenite adsorbent substantially (approximately two order of magnitude) decreases even when several $\mathrm{Pa}$ of water vapor is coexsistent ${ }^{(5)}$. Thus, it can be stated that the effect of coexistent water vapor on the adsorption amount of $\mathrm{CO}_{2}$ is quite small for the MS4A adsorbent.

The authors attempted the prediction of the binary adsorption isotherm shown in Fig. 6 . The vacancy solution model was used for the prediction. In accordance with the vacancy solution model ${ }^{(6)}$, the isotherm of component $i$ in a binary component system, which consists of ideal gases, 1 and 2 (component 3 is the vacancy), is written as

$$
\begin{gathered}
p_{i}=\gamma_{i}^{s} x_{i} n_{m}^{s} \frac{n_{i}^{s, \infty}}{n_{m}^{s, \infty} b_{i}} \Lambda_{i 3} \exp \left(\Lambda_{3 i}-1\right) \exp \left(\frac{\pi \bar{a}_{i}}{R T}\right) \\
-\frac{\pi \bar{a}_{i}}{R T}=\left(1+\frac{n_{m}^{s, \infty}-n_{i}^{s, \infty}}{n_{m}^{s}}\right) \ln \left(\gamma_{3}^{s} x_{3}^{s}\right) \\
\ln \gamma_{i}^{s}=1-\ln \left(x_{i}^{s}+x_{j}^{s} \Lambda_{i j}+x_{3}^{s} \Lambda_{i 3}\right)-\left(\frac{x_{i}^{s}}{x_{i}^{s}+x_{j}^{s} \Lambda_{i j}+x_{3}^{s} \Lambda_{i 3}}+\frac{x_{j}^{s} \Lambda_{j i}}{x_{i}^{s} \Lambda_{j i}+x_{j}^{s}+x_{3}^{s} \Lambda_{j 3}}\right. \\
\left.+\frac{x_{3}^{s} \Lambda_{3 i}}{x_{i}^{s} \Lambda_{3 i}+x_{j}^{s} \Lambda_{3 j}+x_{3}^{s}}\right) \quad(\text { for } i, j=1,2 \text { or } 2,1)
\end{gathered}
$$


$\ln \gamma_{3}^{s}=1-\ln \left(x_{1}^{s} \Lambda_{31}+x_{2}^{s} \Lambda_{32}+x_{3}^{s}\right)$

$$
-\left(\frac{x_{1}^{s} \Lambda_{13}}{x_{1}^{s}+x_{2}^{s} \Lambda_{12}+x_{3}^{s} \Lambda_{13}}+\frac{x_{2}^{s} \Lambda_{23}}{x_{1}^{s} \Lambda_{21}+x_{2}^{s}+x_{3}^{s} \Lambda_{23}}+\frac{x_{3}^{s}}{x_{1}^{s} \Lambda_{31}+x_{2}^{s} \Lambda_{32}+x_{3}^{s}}\right)
$$

$x_{i}^{s}=\frac{x_{i} n_{m}^{s}}{n_{m}^{s, \infty}} \quad(i=1$ or 2$)$

$x_{3}^{s}=1-\frac{n_{m}^{s}}{n_{m}^{s, \infty}}$

$n_{m}^{s, \infty}=x_{1} n_{1}^{s, \infty}+x_{2} n_{2}^{s, \infty}$

$x_{i}=\frac{n_{i}^{s}}{n_{m}^{s}}$

$n_{m}^{s}=n_{1}^{s}+n_{2}^{s}$

The activity coefficients for adsorbates 1 and 2 are

$\Lambda_{12}=\frac{V_{2}^{L}}{V_{1}^{L}} \exp \left\{\frac{-\left(\lambda_{12}-\lambda_{11}\right)}{R T}\right\}$

$\Lambda_{21}=\frac{V_{1}^{L}}{V_{2}^{L}} \exp \left\{\frac{-\left(\lambda_{21}-\lambda_{22}\right)}{R T}\right\}$

Thus, $-\left(\lambda_{12}-\lambda_{11}\right),-\left(\lambda_{21}-\lambda_{22}\right)$ and $\left(V_{1}^{L} / V_{2}^{L}\right)$ can be dealt with as the parameters optimized in binary-component adsorption systems. If the adsorbate-adsorbate interaction is negligible, $\Lambda_{12}$ and $\Lambda_{21}$ become unity. With this assumption, the binary adsorption isotherm was estimated. For the single component isotherms, the temperature-dependent Wilson parameter model was used. The result of estimation is shown as solid lines in Figs. 6 (a) and (b). As seen in the figures, the adsorption amount of $\mathrm{CO}_{2}$ is considerably underestimated. Thus, the optimization of the parameters $-\left(\lambda_{12}-\lambda_{11}\right),-\left(\lambda_{21}-\lambda_{22}\right)$ and $\left(V_{2}^{L} / V_{1}^{L}\right)$ was attempted. The binary adsorption isotherms calculated using the optimized parameters are shown as broken lines in Figs. 6 (a) and (b). However, the calculation could not well reproduce the experimental result. The reason could be a strongly different affinity of adsorbates $\left(\mathrm{CO}_{2}\right.$ and $\left.\mathrm{H}_{2} \mathrm{O}\right)$ to the MS4A adsorbent or some interaction between adsorbate molecules.

\section{Conclusion}

Adsorption behavior of carbon dioxide on various adsorbents was studied. It was found that a MS4A adsorbent is more suitable for selective recovery of carbon dioxide. Thus, more detailed adsorption characteristics of carbon dioxide were studied for the MS4A adsorbent. The adsorption isotherm of $\mathrm{CO}_{2}$ on the MS4A adsorbent was successfully correlated with the vacancy solution model. Moreover, the influence of coexistent water vapor was investigated. The result suggests that the effect of coexistent water on the adsorption of $\mathrm{CO}_{2}$ on the MS4A adsorbent is considerably small in spite of the stronger affinity of water vapor to the MS4A adsorbent. Thus, it was demonstrated that the MS4A adsorbent is effective for selective recovery of $\mathrm{CO}_{2}$ from the nuclear off-gas. 


\section{References}

(1) Ianovski, D., Munakata, K., Kanjo, S., Yokoyama, Y., Koga, A., Yamatsuki, S., Tanaka, K., Fukumatsu, T., Nishikawa, M. and Igarashi, Y., Journal of Nuclear Science and Technolgy, Vol. 39, No. 11, (2002), pp. 1213-1218.

(2) Munakata K., Fukumatsu, T., Yamatsuki, S., Tanaka, K. and Nishikawa, M., Journal of Nuclear Science and Technolgy, Vol. 36, No. 9, (1999), pp. 818-829.

(3) Munakata K., Yamatsuki, S., Tanakata, K. and Fukumatsu, T., Journal of Nuclear Science and Technolgy, Vol. 37, No. 1, (2000), pp.84-89.

(4) Suwanayuen, S. and Dannar, R.P.: AIChE., Vol. 26, No. 1, (1980), pp. 68-76.

(5) Fukumatsu, T., Munakata, K., Tanakata, K., Yamatsuki, S. and Nishikawa M., Journal of Chem. Eng. Japan, Vol. 32, No. 5, (1999), pp. 662-669.

(6) Suwanayuen, S. and Dannar, R.P.: AIChE., Vol. 26, No. 1, (1980), pp. 76-83. 